\title{
The Influence of Communication and Cosmopoliteness on Quality of Life Perceptions
}

\author{
L. Jeffres ${ }^{1} *$, K. Neuendorf ${ }^{1}$, C. Bracken and D. Atkin ${ }^{2}$ \\ ${ }^{1}$ School of Communication, Cleveland State University ${ }^{2}$ Department of Communication, University of Connecticut
}

\begin{abstract}
This article examines the impact of a sequence of variables that includes people's communication activity and quality of life assessments. Survey results indicate that more cosmopolitan people, those with more diverse interests, those with stronger patterns of media use, and those with higher levels of community knowledge hold stronger assessments of the quality of life available in their community. No such relationships are found for people's assessment of whether the country is headed in the right direction.
\end{abstract}

\section{INTRODUCTION}

People routinely make assessments about the direction their own lives are taking and whether the nation is headed in the right direction. While responses in polls may be treated as fleeting, quality-of-life assessments also are good summary measures of affect that reflect not only personal circumstances and hopes for the future but also the information and impressions gained through mass and interpersonal communication channels.

The growing body of quality of life research often ignores the work conducted by communication researchers (see Andrews, 1986; Campbell, 1981; Sirgy, 2001; Sirgy \& Samli, 1995). People's subjective assessments of their quality of life may be affected not only by the objective environment (Andrews \& Withey, 1976 (1974 in Refs.); Headley et al., 1991) but also by their personal assessments based on information gained through media and interpersonal channels. This process involves a comparative element, as people make judgments based not only on their own experiences and circumstances but also on messages about their situation and how things are going elsewhere (Campbell et al., 1976). Inglehart and Rabier (1986), Michalos (1986), and others propose an aspiration-adjustment model where the perceived quality of life reflects a gap between aspirations and one's perceived situation. Although aspirations may be internally derived, we also conclude what's possible--or what's desirable--by learning about the quality of life elsewhere. Thus, quality of life assessments are affected by personal experiences, aspirations and hopes that reflect our assessment of what's achievable elsewhere, and messages that tell us about our own immediate environment.

The quality-of-life literature shows that objective conditions influence our satisfaction with life, but subjective factors also are important. Indicators related to QOL assess-

\footnotetext{
*Address Correspondence to this Author at the School of Communication, Cleveland State University, USA; Tel: 216-687-5099; Fax: 216-687-5435; E-mail: 1.jeffres@csuohio.edu

${ }^{i}$ Younger adults are less satisfied with where they live (Brennan, 1986); levels of satisfaction for all aspects of life except health rise with age (Campbell et al., 1976; Herzog \& Rodgers, 1986). Also see Powell (1998) for "myths of aging" and the quality of life and Abeles, Gift and Ory (1994) for research on factors affecting the quality of life over the life course.

${ }^{\text {ii }}$ Marriage contributes to overall happiness in U.S. and cross-national data (Campbell et al., 1976). Keith and Schafer (1998) looked at three marital types (e.g., equal partners) and the quality of life. Others have examined the quality of life during widowhood (Shea and Schewe,
}

ments over the past 25 years include: life cycle variables, such as age, ${ }^{\mathrm{i}}$ and marital status ${ }^{\mathrm{ii}}$; achievement factors such as income and satisfaction with standard of living, ${ }^{\text {iii }}$ occupation, ${ }^{\text {iv }}$ and education ${ }^{\mathrm{v}}$; ascriptive factors such as nationality, ${ }^{\mathrm{vi}}$ ethnicity, ${ }^{\text {vii }}$ and gender ${ }^{\text {viii }}$; physical factors such as health ${ }^{\text {ix }}$ and physical appearance ${ }^{\mathrm{x}}$; and geographical factors such as where one lives, e.g., urban vs. rural. ${ }^{\mathrm{xi}}$ Over time, people come to accept their circumstances, and people with quite different levels of affluence are similarly satisfied with their circumstances; several clichés capture this scenario: people "rationalize," come to accept their lot in life, or recognize that money doesn't solve all problems. It's useful, then, to examine how communication variables enter the equation, and how people's orientations toward the environment explain differences in assessments.

\footnotetext{
iii Income is positively related to both objective and subjective measures of QOL (Ackerman \& Paolucci, 1983; Campbell, 1981), but income explained only a small part of the variance of subjective QOL in cross-national data (Inglehart \& Rabier, 1986). Frey and Stutzer (2000) found higher income associated with higher levels of happiness in a survey of 6,000 in Switzerland; the unemployed were much less happy than the employed, independent of income. Also see Cummins (2000), Eckersley (2000), Frey and Stutzer (2001), Graham and Pettinato (2001), Hellevik (2003), Ott (2001), Schyns (2001), Sirgy (1998), Tsou and Liu (2001) and Tatzel (2003). Finding differences in subjective well-being by country but the same relationship between consumption and well-being within country, Ahuvia (2002) proposes that economic development increases consumption, creating more individualistic cultures that encourage people to pursue personal happiness over honor and meeting social obligations.

iv Occupation makes minor contributions overall; executives and professionals are highest in perceived QOL and the unemployed are lowest ranking on QOL. Job satisfaction was related to overall QOL perceptions (Michalos, 1986). Also see Warburton and Suiter (1996) for the impact of job dissatisfaction on quality of life.

${ }^{v}$ Education is unrelated to QOL or only modestly related, Campbell et al. (1976) note, but modest relationships were found in cross-national data.

${ }^{\text {vi }}$ International comparisons show many similarities in perceived QOL (Inglehart \& Rabier, 1986; Szalai \& Andrew, 1980).

${ }^{v i i}$ Ethnic differences on QOL have been found but there is an interaction between race and income (Campbell et al., 1976).

viii Bryant and Veroff (1986) found men and women use the same six dimensions in making personal QOL assessments. Also see Camporese, Freguja and Sabbadini (1998) for a recent survey that looked at a woman's lifestyle and quality of life.

${ }^{\text {ix }}$ Health is important for older people and a priority when problems occur (Campbell et al., 1976). Bowling (1997) looks at measurement of health as a factor in one's quality of life.

${ }^{x}$ People judged as more attractive report they are more positive but not "more satisfied" with their lives (Campbell et al., 1976).

${ }^{x i}$ Urbanites are less satisfied (Fernandez \& Kulik, 1981). Also see Parfect and Power (1997) for planning as a factor affecting urban quality of life.
} 
A concept that captures differences in how people orient themselves to their environment is found in "cosmopoliteness," which has been invoked as a construct reflecting people's broader outlook on life. Cosmopoliteness has been linked to education and social categories, particularly in the diffusion of innovations literature (Rogers, 2003; also see McLeod et al., 1996, Neuwirth, Salmon \& Neff, 1989). Given a particular context, quality of life assessments of those with broader interests and involvement in a more diverse network-including interpersonal and mass communication channels - should differ from those with more narrow interests and a more homogeneous network.

One interpretation of "cosmopoliteness" stresses the extent to which one is oriented toward the community in which one lives or is oriented beyond that toward the nation and international context (e.g., Cunningham, Cunningham \& English, 1974). "Cosmopoliteness" also has been conceptualized to refer to identification with a broader context, beyond one's nation or culture, as attitudes showing more tolerance of ideas or cultures other than one's own (Robinson \& Zill, 1997), and as appreciation-understanding of contexts and cultures beyond one's own (Merton, 1957).

People who are more cosmopolitan in terms of local orientation, cultural identification, and cultural appreciation also should have a more diverse communication network of interpersonal and mass communication channels, although the composition of one's personal communication network is not entirely a matter of choice. People with a more cosmopolitan orientation should have broader interests in the world around them and would learn more about the environment from their media and interpersonal channels from that network. This knowledge about the environment would be used in making broader assessments about the quality of life available in their immediate context as well as in the larger nation. The following sequence of variables encapsulates this dynamic:

$\begin{array}{lcc}\begin{array}{c}\text { Social } \\ \text { Categories } \rightarrow\end{array} & \begin{array}{c}\text { Cosmo } \\ \text { orientation } \rightarrow\end{array} & \begin{array}{c}\text { Broader } \\ \text { interests } \rightarrow\end{array} \\ \text { IP Com\& } & \text { Greater } & \text { QOL } \\ \text { MM Use } \rightarrow & \text { knowledge } \rightarrow & \text { Assessments }\end{array}$

The sources of influence on people's quality of life assessments include personal experiences and observation about their objective environment, and these are often reflected in the social categories that measure status and condition, including education and income, gender and ethnicity. ${ }^{\text {xii }}$ Status has been linked to a cosmopolitan orientation in the diffusion literature, as noted earlier. Here our focus is on an interpretation of cosmopoliteness reflecting a stronger appreciation of other cultures and a broader identification. These in turn should be linked to stronger interests in public affairs in general, but particularly in news about what's going on in other parts of the country and around the world--a notion captured by the diffusion of innovations literature. When people interact with others or turn to the mass media, they are more likely to seek out news, topics, issues and events that reflect these broader interests, and this should result in higher levels of knowledge about the larger environment, including their communities and the public area in general (Neuendorf et al., 2000). The final step is the formation of assessments about the quality of life in the larger environment. We will examine the relationships between these factors and QOL assessments by asking following:

RQ1: How are quality of life perceptions related to social categories, cosmopoliteness, interests, involvement in mass and interpersonal channels, and environmental knowledge?

\section{METHODS}

Variables were examined in a survey conducted in a diverse Midwest metropolitan area. ${ }^{\text {xiii }}$ Some 351 respondents were interviewed using a computer-aided telephone interviewing (CATI) system, with a response rate of 50 percent. Interviewing was conducted in the evening hours, and the survey was introduced as a metro poll containing a variety of items. Following are the variables as operationalized from the sequence, although further detail can be found in the tables:

Social categories. The survey included common measures of ascriptive (gender, race), achievement (education, household income) and life cycle (age, marital status) variables.

Quality of life assessments. Respondents were asked to assess the quality of life available in the metropolitan area where they lived with the following item: "First, I'd like you to imagine a scale from 0 to 10 , with 0 being the worst place to live and 10 being the best place to live. On this scale, how would you rank the [name of city] area?"

The standard item used in national public opinion polls to indicate satisfaction with the country was used for a national QOL assessment. Using a 0-10 scale, where 0 meant they strongly disagreed and 10 meant they strongly agreed, respondents were asked how much they agreed that "The country is headed in the right direction."

Diversity of interests in environment. Respondents were told, "Now, I'm going to ask how interested you are in a variety of things, using a $0-10$ scale where 0 means you're not at all interested and 10 means you're extremely interested. You may give any number between 0 and 10 to indicate how interested you are." Some 16 items were included, ranging from entertainment and politics to cooking, the arts, religion and outer space. For the analysis, the items were standardized and a summary score computed for an overall measure of "diversity of interests" (alpha $=.76)$. Three additional interest items were utilized in the cosmopoliteness measure that follows.

Cosmopoliteness. Several different types of items were used to measure cosmopoliteness. Respondents were asked

\footnotetext{
xii Much of the QOL research focuses on the relationship between people's physical and social environment and measures of the quality of life. That relationship is not as strong as might be expected. Campbell $(1981$, pp. 2, 4) notes, "correspondence between our objective conditions and our subjective experience is very imperfect. If we try to explain the population's sense of well-being on the basis of objective circumstances, we will leave unaccounted for most of what we are trying to explain" (also see Diener \& Suh, 1997).

xiii The sample included 56 percent women and 44 percent men. The median age was 40 , with 15 percent age 60 or older and 15 percent age 25 or younger. Twenty percent were high school graduates, 29 percent had some college, and 30 percent were college graduates. The median household income was about $\$ 40,000$. Some 19 percent of respondents were black/African American, two thirds were white/Caucasian, 2 percent were Hispanic, 2 percent Asian and the others mixed or other.
} 
to use a $0-10$ scale (where $0=$ strongly disagree, $5=$ neutral, $10=$ strongly agree) to tell how much they agreed with three items, one focusing on how people see themselves as international citizens ("I think of myself as a citizen of the world."), another focusing on communication with people from different backgrounds ("In any given month, I communicate with people from a wide variety of backgrounds and cultures."), and one emphasizing awareness of events around the world ("I'm more aware of what's going on around the world than most of my friends."). Three additional items asked respondents to use a $0-10$ scale to rate their interest in travel to different countries, current events in other countries, and other cultures. Finally, respondents were asked for the number of times they had traveled outside the United States in the past five years. These items were factor analyzed, with orthogonal (varimax) rotation, yielding two factors. Loading on the first factor, which accounted for 36 percent of the variance, were four items: interest in current events in other countries, interest in travel to different countries, interest in other cultures, and the number of times one has traveled outside the United States in the past five years; the factor was labeled International Focus. ${ }^{\text {xiv }}$ Loading on the second factor were three items--agreeing with the following statements: "I think of myself as a citizen of the world," "In any given month, I communicate with people from a wide variety of backgrounds and cultures," and "I'm more aware of what's going on around the world than most of my friends." Interest in other cultures loaded on the second factor as well. This factor was labeled Cosmopolitan Communication and Attitude; it accounted for 17.3 percent of the variance. ${ }^{\mathrm{xv}}$ Factor scores were retained for use as variables.

Mass and interpersonal channels of communication. Level of activity using mass media and interpersonal communication channels was measured using two strategies. Traditional items were used to measure media use. Respondents were asked how many hours of television they watched yesterday, how many hours they listened to the radio yesterday, how many days last week they read a newspaper, how many different magazines they read regularly, the number of books read in the past six months, the number of borrowed or rented videos watched in the past month, and the number of times in the past month they went out to see a movie in a theater. Responses were standardized and summed up for a measure of overall mass media use.

For a measure of involvement in interpersonal communication channels, respondents were told, "Now, I'd like you to think about the number of people you talked with today. Please indicate how many people you talked with in each of the following." The contexts given were: people in your household, including spouse, children, others; people in your neighborhood, including neighbors or people at local stores, in public places or on public transit; people elsewhere in the city; people in the [metro] area you spoke with on the phone;

\footnotetext{
xiv All items loaded at .70 or higher.

${ }^{x v}$ All variables loaded at .50 or higher on this factor. Communalities for the cosmopolite variables, which represent the proportion of a variable's total variance that is accounted for by the factors, were: interest in current events in other countries, .54; interest in travel to different countries, .54 ; interest in other cultures, .51 ; the number of times one has traveled outside the United States in the past five years, .59; thinking of oneself as a citizen of the world, .68; communicating with people from a wide variety of backgrounds and cultures, .67; and awareness of what's going on around the world compared to friends, .57 .
}

people outside the area you spoke with on the phone. Two variables were derived from these items ${ }^{\mathrm{xvi}}$.

Knowledge of the environment: One set of items tapped knowledge of the immediate environment, the metropolitan area in which respondents lived, while a second set measured knowledge of the larger international environment. The five items used to assess community knowledge covered people, places and events across time. ${ }^{\text {xii }}$ The mean number of correct items was 2.0 (standard deviation $=1.35$ ), with $16.8 \%$ getting none correct, $19.4 \%$ one correct, $26.2 \%$ two correct, $22.5 \%$ three correct, $12.5 \%$ four correct and $2.6 \%$ all five correct. Four items tapped knowledge of the international environment. ${ }^{\text {xviii }}$ The mean number of correct responses was 2.03 (standard deviation $=1.12$ ), with $8 \%$ getting none correct, $24 \%$ one correct, $33 \%$ two correct, $24 \%$ three correct and $10 \%$ all four correct.

\section{RESULTS}

Hierarchical regression analysis was used to answer the research question, with variables entered in the same order as reflected in the sequence: social categories, cosmopoliteness (factor scores representing cosmopolitan attitude and international interests-travel), diversity of interests (single summary measure across 16 items), activity in mass and interpersonal communication channels (summary media use score and the two measures of interpersonal communication links across contexts), and finally, two measures of knowledge of the environment (community knowledge and international public affairs knowledge). In the first regression, the assessment of the community quality of life was the criterion variable.

Note: For each regression variables were entered as follows: social categories=household income, education level, gender, married marital status, Caucasian ethnicity; cosmopoliteness $=$ cosmopolitan attitude, international intereststravel; diversity of interests $=16$ item scale score; activity in communication channels=media use index, raw score of interpersonal links across contexts, summary index of standardized scores of interpersonal links across contexts; knowledge indexes=five-item metro knowledge index, fiveitem international public affairs knowledge index.

As Table 1 shows, social categories have little impact in explaining the QOL assessment, but the impact of cosmopoliteness approaches significance ( $\mathrm{F}$ Ch. $=2.9, \mathrm{p}<.055)$, and it's the measure of international interests and travel that is significant. A cosmopolitan attitude is unimportant. The broader measure of diversity of interests across 16 domains

\footnotetext{
${ }^{x v i}$ First, a summary score of the number of people talked to was computed. Since this measure is merely a summary score, one category could overwhelm the others, e.g. someone could work with the public and engage in many personal conversations but have little interpersonal contact outside work. For a second measure, the items were standardized and a summary score computed for a measure of the strength of interpersonal communication links across contexts; this measure thus reflects a broader measure of the strength of interpersonal connections.

xvii One asked respondents to identify from five options the current president of the city council (correctly chosen by $43 \%$ ), one asked respondents to pick from six choices the neighborhood in which the metro zoo was located (correctly identified by $50 \%$ ), one asked which of five individuals was the new owner of the professional baseball team (58\% correct), one asked respondents to select from six options the founder of a wellknown suburban community with a national reputation (26\% correct), and one asked which of six businesses did not have its headquarters in the metro region (25\% correct) xviii One asked where Kosovo was located (60\% correct), a second asked whether conservatives or moderates had won the recent parliamentary elections in Iran (31\% correct), a third asked for the major religion in Indonesia ( $28 \%$ correct), and a fourth asked which continent had been most devastated by AIDS ( $83 \%$ correct).
} 
Table 1. Predicting Assessment of Quality of Life Available in Metropolitan Area

\begin{tabular}{|c|c|c|c|c|}
\hline & $\mathbf{R}$ & $\begin{array}{l}\text { R Sq. } \\
\text { Change }\end{array}$ & $\begin{array}{c}\text { F } \\
\text { Change }\end{array}$ & $\begin{array}{c}\text { Standardized } \\
\text { Betas }\end{array}$ \\
\hline Social Categories & .097 & .009 & .38, n.s. & \\
\hline Cosmopoliteness & .182 & .024 & $\begin{array}{l}2.9 \\
\mathrm{p}=.055\end{array}$ & $\begin{array}{l}\text { Intl. interests- } \\
\text { travel } \beta=.15 \text {, } \\
\mathrm{p}=.02\end{array}$ \\
\hline $\begin{array}{l}\text { Diversity of } \\
\text { Interests }\end{array}$ & .223 & .017 & $\begin{array}{l}4.2, \\
p=.04\end{array}$ & $\begin{array}{l}\text { Diversity of } \\
\text { interests } \beta \\
=.16, p=.04\end{array}$ \\
\hline $\begin{array}{l}\text { Communication } \\
\text { Indexes }\end{array}$ & .273 & .025 & $\begin{array}{l}2.2, \\
p=.10\end{array}$ & $\begin{array}{l}\text { Media use } \\
\text { index } \beta=.15 \text {, } \\
\mathrm{p}=.02\end{array}$ \\
\hline $\begin{array}{l}\text { Knowledge } \\
\text { Indexes }\end{array}$ & .356 & .052 & $\begin{array}{l}6.9 \\
p=.001\end{array}$ & $\begin{array}{l}\text { Community } \\
\text { knowledge } \beta \\
=.21, \mathrm{p}=.005 \text {; } \\
\text { Intl. knowl- } \\
\text { edge } \beta=-.23 \text {, } \\
\mathrm{p}=.002\end{array}$ \\
\hline & \multicolumn{4}{|c|}{$\mathrm{R}=.356, \mathrm{R} \mathrm{Sq} .=.126, \mathrm{~F}=2.4, \mathrm{p}=.004$} \\
\hline \multicolumn{5}{|c|}{ Predicting Assessment of Direction Country is Headed } \\
\hline Social Categories & .201 & .040 & 1.68 , n.s. & $\begin{array}{l}\text { Age } \beta=.13, \\
p=.053\end{array}$ \\
\hline Cosmopoliteness & .226 & .051 & 1.33 , n.s. & \\
\hline $\begin{array}{l}\text { Diversity of } \\
\text { Interests }\end{array}$ & .254 & .064 & $\begin{array}{l}3.36 \\
p=.068\end{array}$ & $\begin{array}{l}\text { Diversity of } \\
\text { interests } \beta \\
=.14, \mathrm{p}=.068\end{array}$ \\
\hline $\begin{array}{l}\text { Communication } \\
\text { Indexes }\end{array}$ & .259 & .067 & .22 , n.s. & \\
\hline $\begin{array}{l}\text { Knowledge } \\
\text { Indexes }\end{array}$ & .265 & .070 & .41, n.s. & \\
\hline & \multicolumn{4}{|c|}{$\mathrm{R}=.265$, R Sq. $=.07, \mathrm{~F}=1.25$, n.s. } \\
\hline
\end{tabular}

also has a positive impact on QOL assessment (beta=.16, $\mathrm{p}=04)$. The three measures of activity in communication channels collectively do not explain additional variance in the metro QOL assessment ( $\mathrm{F} \mathrm{Ch.=2.1,} \mathrm{p}=.10)$, but the beta for the media use measure is significant (beta $=.15, \mathrm{p}=.02$ ). Finally, both knowledge indexes have an impact in the final step $(\mathrm{F} \mathrm{Ch} .=6.9, \mathrm{p}=.001)$, but, while community knowledge has a positive impact on community QOL assessment (beta=.21, p=.005), international public affairs knowledge is negatively associated (beta $=-.23, \mathrm{p}=.002$ ). In the final equation, all significant predictors retain their status, with one exception, the measure of diversity of interests drops just below the standard level of acceptance (beta=.15, $\mathrm{p}=.06$ ).

In the second regression, the criterion variable was respondents' assessment of whether the country was headed in the right direction. As Table 1 shows, none of the blocks of variables are significant predictors, although the measure of diversity of interests comes close $(\mathrm{F} \mathrm{Ch} .=3.4$, beta $=.14$, $\mathrm{p}=.068$ ). In addition, the final equation fails the significance tests, suggesting that our affective measure of the national QOL is a more fleeting political statement than is a broader assessment of where the country's heading.

\section{DISCUSSION}

In its exploration of communication influences, the present study finds that people's assessment of the quality of life available in their community is not merely a reflection of demographics and the objective conditions people face. People with a more cosmopolitan orientation-interest in other cultures and countries--and those with more diverse interests see a more positive environment, suggesting that "the grass isn't always greener" and comparisons may make some residents more contented. And, while the media are assailed for presenting bad news (e.g., Gerbner et al., 1986), here the media use index is a positive predictor of community QOL. Knowledge also makes a contribution, so that those who are more aware of their community have a more positive outlook. ${ }^{\text {xix }}$

One explanation for these findings might lie in that fact that the rapidly fragmenting media environment is presenting a mixed set of messages, which can range from crime reporting in mass media to highly tailored web and interpersonal (e.g., email) channels that can cultivate a more positive sense of civic involvement (e.g., Bucy, Gantz, \& Zhang, 2007; Jeffres, 2007). Although only sporadically examined in the communication literature, often in conjunction with such concepts as diffusion of innovations, the concept of cosmopoliteness should assume greater importance as the knowledge economy unfolds (e.g., Rogers, 2003). As communities and nations vie for a relatively fixed pool of knowledge workers, an emerging class to which their fortunes are increasingly tied, the present results suggest that a strong media infrastructure may be critical in maintaining QOL assessments. And, as Putnam (1996) argues, the enhancement of a region's "social capital" is contingent on the ability to recruit and retain this new creative class.

In sum, perhaps the most encouraging aspect of our findings is the positive link between media use and QOL assessments, which contradicts past work suggesting that heavy media use has contributed to a sense of civic malaise and disengagement (e.g., Mindich, 2004). Given that media are now shrinking the globe, and new media like the Internet are linked with cosmopolitan attitudes (e.g., Jeffres et al., 2004), it will be important to assess these relationships between communication, cosmopoliteness and QOL assessments in later work.

\section{REFERENCES}

Abbe, A., Tkach, C., \& Lyubomirsky, S. (2003). The art of living by dispositionally happy people. Journal of Happiness Studies, 4, 385-404.

Abeles, R., Gift, H., \& Ory, M. (Eds.). (1994). Aging and quality of life. New York: Springer Pub. Co.

Ackerman, N. \& Paolucci, B. (1983). Objective and subjective income adequacy: Their relationship to perceived life quality measures. Social Indicators Research, 12, 25-48.

Ahlbrandt, R.S. Jr. (1986). Using research to build stronger neighborhoods: A study of Pittsburgh's neighborhoods. In R.B. Taylor (Ed.), Urban neighborhoods, research and policy (pp. 285-309). New York: Praeger.

Ahuvia, A.C. (2002). Individualism/collectivism and cultures of happiness: A theoretical conjecture on the relationship between consumption, culture and subjective well-being at the national level. Journal of Happiness Studies, 3, 23-36. 
Andrews, F. M. (Ed.). (1986). Research on the quality of life. Ann Arbor Social Research. Ann Arbor: University of Michigan.

Andrews, F., \& Withey, S. (1974). Developing measures of perceived life quality: Results from several national surveys. Social Indicators, 1 , $1-26$.

Bowling, A. (1997). Measuring health: A review of quality of life measurement scales. Philadelphia, PA: Open University Press.

Bowling, A. \& Windsor, J. (2001). Toward the good life: A population survey of dimensions of quality of life. Journal of Happiness Studies, 2, 55-82.

Brennan, J. (1986). Majority of American like where they live. A report on ABC News Washington Post Poll conducted February. New York City: ABC News.

Bryant, F. \& Veroff, J. (1986). Dimensions of subjective mental health in American men and women. In F. Andrews (Ed.), Research on the Quality of Life (pp. 117-146). Ann Arbor, MI: Institute for Social Research, University of Michigan.

Bucy, E., Gantz, W., \& Wang, Z. (2007). Media technology and the 24 hour newscycle. In C. Lin \& D. Atkin (Eds.), Communication technology and social change: Theory and implications (pp. 143163). Mahwah, NJ: LEA.

Campbell, A. (1981). The sense of well-being in America: Recent patterns and trends. New York: McGraw-Hill Book Co.

Campbell, A., Converse, P., \& Rodgers, W. (1976). The quality of American life. New York: Russell Sage.

Camporese, R., Freguja, C., \&, Sabbadini, G. (1998). Time use by gender and quality of life. Social Indicators Research, 44, 119-144.

Cline, M. (1995). Supporting the quality of life of single parent homeless families: A case study. In J. Sirgy \& A. Samli (Eds.), New dimensions in marketing/ quality-of-life research (pp. 137-150). Westport, CT: Quorum Books.

Cohen, A. B. (2002). The importance of spirituality in well-being for Jews and Christians. Journal of Happiness Studies, 3, 287-310.

Csikszentmihalyi, M. \& Hunter, J. (2003). Happiness in everyday life: The uses of experience sampling. Journal of Happiness Studies, 4, 185199.

Cummins, R. A. (2000). Personal income and subjective well-being: A review. Journal of Happiness Studies, 1, 133-158.

Cunningham, W.H., Cunningham, I.C.M., \& English, W. D. (1974). Sociopsychological characteristics of undergraduate marijuana users. Journal of Genetic Psychology, 125, 3-12.

Diener, E. \& Lucas. R. E. (2000). Explaining differences in societal levels of happiness: Relative standards, need fulfillment, culture, and evaluation theory. Journal of Happiness Studies, 4, 41-78.

Diener, E. \& Suh, E. (1997). Measuring quality of life: Economic, social and subjective indicators. Social Indicators Research, 40 (1-2), 189-216.

Easterlin, R.A. (2001). Life cycle welfare: Trends and differences. Journal of Happiness Studies, 2, 1-12.

Eckersley, R. (2000). The mixed blessings of material progress: Diminishing returns in the pursuit of happiness. Journal of Happiness Studies, 1, 267-292.

Fernandez, R.M. \& Kulik, J. C. (1981). A multilevel model of life satisfaction: Effects of individual characteristics and neighborhood composition. American Sociological Review, 46, 840-850.

Ferriss, A.L. (2002). Religion and the quality of life. Journal of Happiness Studies, 3, 199-215.

Frey, B.S. \& Stutzer, A. (2000). Happiness prospers in democracy. Journal of Happiness Studies, 1, 79-102.

Frey, B.S. \& Stutzer, A. (2001). Happiness and economics. Princeton, NJ: Princeton University Press.

Fried, M. (1986). The neighborhood in metropolitan life: Its psychosocial significance. In R.B. Taylor (Ed.), Urban neighborhoods, research and policy (pp. 331-363) New York, Praeger.

Gerbner, G., Gross, L., Morgan, M., \& Signorielli, N. (1986). Living with television: The dynamics of the cultivation process. In J. Bryant \& D. Zillman (Eds.), Perspectives on media effects (pp. 17-40). Hillsdale, NJ: Erlbaum.

Graham, C. \& Pettinato, S. (2001). Happiness, markets and democracy: Latin America in comparative perspective. Journal of Happiness Studies, 2, 237-268.

Groot, W., \& Van Den Brink, H. M. (2002). Age and education differences in marriages and their effects on life satisfaction. Journal of Happiness Studies, 3, 153-165.
Headley, B., Veenhoven, R., \& Wearing, A. (1991). Top-down versus bottom-up theories of subjective well-being. Social Indicators Research, 24, 81-100.

Hellevik, O. (2003). Economy, values and happiness in Norway. Journal of Happiness Studies, 4, 243-283.

Hertzog, A. \& Rodgers, W. (1986). Satisfaction among older adults. In F. Andrews (Ed.). Research on the quality of life (pp. 235-251). Ann Arbor, MI: Institute for Social Research, University of Michigan.

Heylighen, F. \& Bernheim, J. (2000). Global progress II: Evolutionary mechanisms and their side-effects. Journal of Happiness Studies, 1, 351-374.

House, J.S. (1986). Social support and the quality and quantity of life. In F.M. Andrews (Ed.), Research on the Quality of Life (pp. 253-269). Ann Arbor, MI: Institute for Social Research, University of Michigan.

Ingelhart, R. \& Rabier, J. (1986). Aspirations adapt to situations-but why are the Belgians so much happier than the French? In F. Andrews (Ed.), Research on the quality of life (pp. 1-56). Ann Arbor, MI: Institute for Social Research, University of Michigan.

Jeffres, L. (2007). Media technology in civic life. In C. Lin and D. Atkin (Eds.), Communication technology and social change: Theory and implications (pp. 125-141). Mahwah, NJ: LEA.

Jeffres, L., Atkin, D., Bracken, C., \& Neuendorf, K. (2004). Cosmopoliteness in the Internet age. Journal of Computer Mediated Communication, 10 (1), Article 2.

Jeffres, L. \& Dobos, J. (1995). Separating people's satisfaction with life and public perceptions of the quality of life in the environment. Social Indicators Research 34, 181-211.

Jeffres, L.W., Neuendorf, K., \& Atkin, D. (2000). Media use patterns and public perceptions of the quality of life (pp. 369-385). In Proceedings of the Second International Conference on Quality of Life in Cities, Volume 2. (pp. 369-385) Singapore: The National University of Singapore.

Kasser, T. \& Sheldon, K. M. (2002). What makes for a merry Christmas?" Journal of Happiness Studies, 3, 313-329.

Keith, P. \& Schafer, R. (1998). Marital types and quality of life. Marriage and Family Review 27, 19-35.

Lane, R.E. (2000). Diminishing returns to income, companionship-and happiness. Journal of Happiness Studies, 1, 103-119.

Lykken, D. (2000). Happiness: The nature and nurture of joy and contentment. New York: St. Martin's Press, Inc.

McLeod, J.M., K. Daily, K., Guo, Z., Eveland, W. B., Bayer, J., Yang, S., \& Wang, H. (1996). Community integration, local media use and democratic processes. Communication Research 23, 179-209.

Merton, R.E. (1957). Social theory and social structure. Glencoe, IL: Free Press.

Michalos, A. (1986). Job satisfaction, marital satisfaction and the quality of life: A review and preview. In F. Andrews (Ed.), Research on the quality of life (pp. 57-83). Ann Arbor, MI: Institute for Social Research, University of Michigan.

Mindich, D. (2004). Tuned out. New York: Oxford.

Munoz-Sastre, M.T., Vinsonneau, G., Neto, F., Girard, M., \& Mullet, E. (2003). Forgivingness and satisfaction with life. Journal of Happiness Studies, 4, 323-335.

Neuendorf, K., Jeffres, L.W., Skalski, P., \& Atkin, D. (2000). Perceptions of quality of life and affective characteristics: An urban examination. In Proceedings of the Second International Conference on Quality of Life in Cities, Volume 2 (pp. 401-422). Singapore: The National University of Singapore.

Neuwirth, K., Salmon, C. T., \& Neff, M. (1989). Community orientation and media use. Journalism Quarterly, 66, 31-39.

Ott, J. (2001). Did the market depress happiness in the U.S.? Journal of Happiness Studies, 2, 433-443.

Parfect, M. \& Power, G. (1997). Planning for urban quality: Urban design in towns and cities. New York. Routledge.

Powell, D. (1998). The nine myths of aging: Maximizing the quality of later life. New York: W.H. Freeman.

Putnam, R. (1996). The strange disappearance of civic America. Journal of Democracy, 6, 34-48.

Robinson, J.P. \& Zill, N. (1997). Matters of culture. American Demographics, $19,48-52$.

Rogers, E.M. (2003). Diffusion of innovations, $\left(5^{\text {th }}\right.$ Ed). New York: Free Press.

Saris, W.E. (2001). What influences subjective well-being in Russia? Journal of Happiness Studies, 2, 137-146. 
Schuessler, K. \& Fisher, G. (1985). Quality of life research and sociology. Annual Review of Sociology, 11, 129-149.

Schyns, P. (2001). Income and satisfaction in Russia. Journal of Happiness Studies, 2, 173-204.

Shea, L. \& Schewe, C. (1995). Enhancing the quality of life during widowhood: A marketing challenge. In J. Sirgy and A. Samli (Eds.), New Dimensions in Marketing/Quality-of-Life Research 1pp. (137-150). Westport, CT: Quorum Books.

Sirgy, M.J. (2001). Handbook of quality-of-life research: An ethical marketing perspective. The Netherlands: Kluwer Academic Publishers.

Sirgy, M.J. (1998). Materialism and quality of life. Social Indicators Research, 43, 227-260.

Sirgy, M., Lee, D., Kosenko, R., Meadow, H., Rahtz, D., Cicic, M., Jin, G., Yarsuvat, D., Blenkhorn, D., \& Wright, N. (1998). Does television viewership play a role in the perception of quality of life? Journal of Advertising, 27, 125-142.
Sirgy, J. \& Samli, A. (1995). New dimensions in marketing/ quality-of-life research. Westport, CT: Quorum Books.

Swinyard, W.R., Kau, A.-K, \& Phua, Y. (2001). Happiness, materialism and religious experience in the U.S. and Singapore. Journal of Happiness Studies, 2, 13-32.

Szalai, A. \& Andrews, F.M. (1980). The quality of life: Comparative studies. Beverly Hills, CA: Sage Publications.

Tatzel, M. (2003). The art of buying: Coming to terms with money and materialism. Journal of Happiness Studies, 4, 405-435.

Tsou, M-W. \& Liu, J.-T. (2001). Happiness and domain satisfaction in Taiwan. Journal of Happiness Studies, 2, 269-288.

Veenhoven, R. (2000). The four qualities of life. Journal of Happiness Studies, 1, 1-39.

Veenhoven, R. (2003). Notions of art-of-living, Journal of Happiness Studies, 4, 345-349.

Warburton, D. \& Suiter, J. (1996). The costs of job dissatisfaction. In D. Warburton and N. Sherwood (Eds.), Pleasure and quality of life (pp. 13-28). New York: Wiley. 